\title{
EUS-guided coiling of rectal varices
}

\author{
Roy J. Mukkada, MD, DNB, ${ }^{1}$ Pradeep G. Mathew, MD ${ }^{1}$ V. Francis Jose, MD, DM, ${ }^{1}$ \\ Antony Paul Chettupuzha, MD, DM, ${ }^{1}$ Rajesh Antony, MD, ${ }^{2}$ Abraham Koshy, MD, DM ${ }^{3}$
}

Rectal varices are reported in about $38 \%$ to $94 \%$ of patients with portal hypertension ${ }^{1}$; however, they present with significant bleeding in fewer than $5 \%$ of patients. ${ }^{2}$ The current treatment options for bleeding rectal varices include endoscopic injection sclerotherapy (EIS), endoscopic band ligation, ${ }^{2}$ transjugular intrahepatic portosystemic shunt placement, balloon-occluded retrograde transvenous obliteration, ${ }^{3}$ and cyanoacrylate alone ${ }^{4}$ or a combination of cyanoacrylate and coils. ${ }^{5}$ We report a case of rectal variceal bleeding managed with EUS-guided coiling alone.

A 65-year-old man with alcohol-related decompensated cirrhosis of the liver with portal hypertension (Model for End-Stage Liver Disease [MELD] score of 25) presented with recurrent lower GI bleeding to a local hospital, where he underwent multiple sessions of sclerotherapy for hemorrhoids. He had received multiple transfusions of packed red blood cells and fresh frozen plasma at the local hospital, but inasmuch as his bleeding persisted, he was referred to our center.

At our center, after initial hemodynamic stabilization, sigmoidoscopy revealed large rectal varices (Fig. 1), not hemorrhoids, as previously thought, with active bleeding

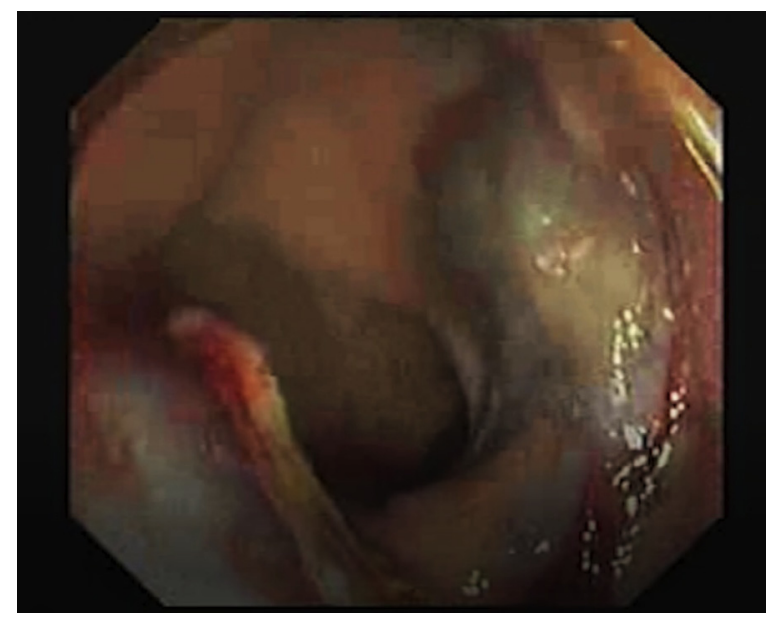

Figure 1. Colonoscopic view showing large rectal varix. from 2 sites (Fig. 2). Rectal varices were distinguished from hemorrhoids. Rectal varices were more than $4 \mathrm{~cm}$ above the dentate line. ${ }^{6}$ EIS was done with $16 \mathrm{~mL}$ sodium tetradecyl sulfate $1 \%$ into 4 sites, but we were unable to achieve hemostasis. Because of persistent active bleeding, $2 \mathrm{~mL}$ of cyanoacrylate was injected under direct vision onto the bleeding site (Video 1, available online at www.VideoGIE.org). Hemostasis was achieved, and the patient was discharged.

A week later he presented again with lower GI bleeding. A repeat sigmoidoscopy showed a thrombosed area of previous glue injection. No soft areas could be identified on probing with closed biopsy forceps.

As our experience with coils for the management of gastric varices and duodenal varix was good, ${ }^{7}$ we opted to do an EUS to assess the feasibility of EUS-guided coiling. EUS showed large, submucosal, rectal collateral varices (Fig. 3). The Doppler study showed good flow velocity (Fig. 4). EUS-guided coiling was done using a 19G needle as previously reported. ${ }^{5}$ The varix was punctured with a single sharp jab, the stylet was withdrawn, and two 5-mm coils were deployed under EUS guidance. Selection of the coils was based on the diameter of the varix, which was $5.9 \mathrm{~mm}$. Because larger

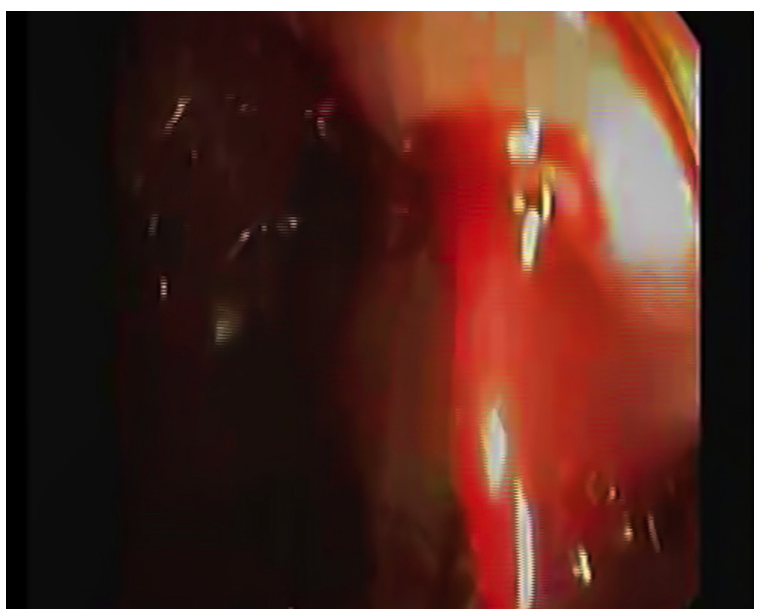

Figure 2. Colonoscopic view showing active bleeding from rectal varix. 


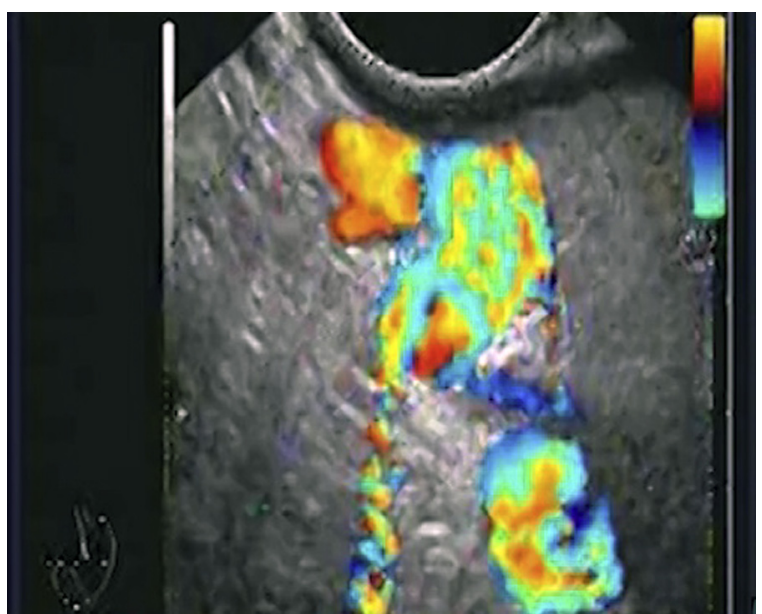

Figure 3. EUS color Doppler view showing large rectal varix.

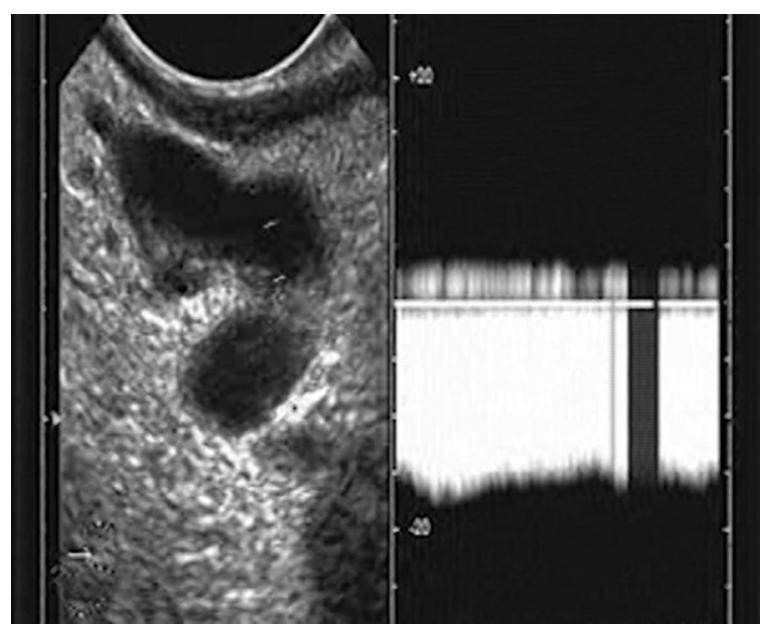

Figure 4. Pre-embolization pulse wave spectral Doppler tracing of rectal varices showing good flow.

coils of the same size or bigger were unavailable, we chose to place two 5-mm coils. A repeat Doppler study done immediately after coil deployment showed significant reduction of flow. The absence of Doppler flow was reconfirmed after 2 minutes, and the needle was removed (Fig. 5).

During EUS, rectal varices are seen to be rounded, oval, or longitudinal hypoechoic areas in the submucosa. Perirectal collateral veins may also be seen outside the rectal wall. ${ }^{8}$ Sharma and Somasundaram ${ }^{9}$ described EUS-guided glue injection as a viable option in bleeding rectal varices. Romero-Castro et $\mathrm{al}^{10}$ described their case series of EUS-guided coiling for rectal varices for which they had used multiple coils. Weilert et $\mathrm{al}^{5}$ described the use of coils and glue in their series and used multiple glue injections and coils in their study; however, in the present case there was no further

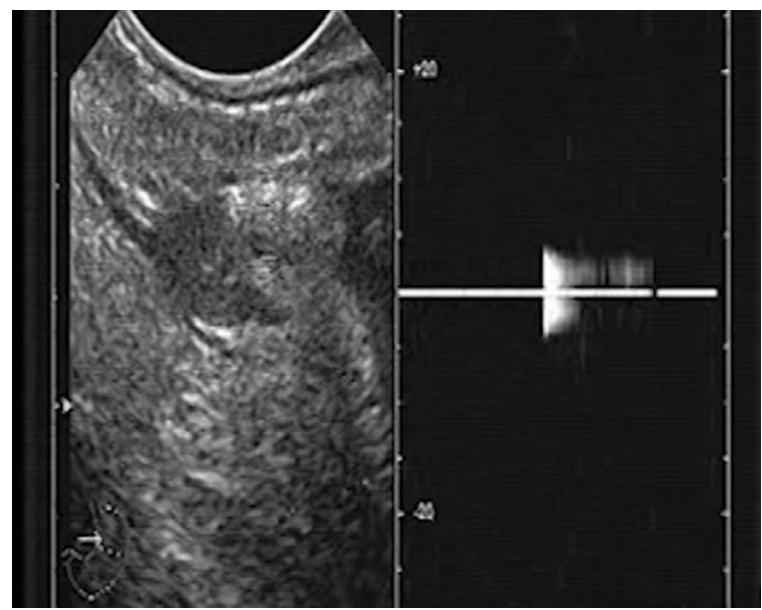

Figure 5. Post-embolization pulse wave spectral Doppler showing absence of flow.

requirement for injection of glue or for coil because Doppler flow had disappeared completely with the initial deployment of 2 coils. Messallam et $\mathrm{al}^{11}$ reported the use of coils along with glue for bleeding rectal varices, but they completed the procedure in 2 sessions and required more glue. Our patient was followed up for 3 months, and he died as a result of adverse events related to decompensated cirrhosis, not because of the bleeding.

In patients with cirrhosis and portal hypertension with severe lower GI bleeding, the possibility of rectal varices should be considered. EUS-guided coiling of a rectal varix is an option to control bleeding.

\section{DISCLOSURE}

All authors disclosed no financial relationships relevant to this publication.

Abbreviations: EIS, endoscopic injection sclerotherapy; MELD, Model for End-Stage Liver Disease.

\section{REFERENCES}

1. Misra SP, Dwivedi M, Misra V. Prevalence and factors influencing hemorrhoids, anorectal varices, and colopathy in patients with portal hypertension. Endoscopy 1996;28:340-5.

2. Coelho-Prabhu N, Baron TH, Kamath PS. Endoscopic band ligation of rectal varices: a case series. Endoscopy 2010;42:173-6.

3. Al Khalloufi K, Laiyemo AO. Management of rectal varices in portal hypertension. World J Hepatol 2015;7:2992-8.

4. Romero-Castro R, Ellrichmann M, Ortiz-Moyano C, et al. EUS-guided coil versus cyanoacrylate therapy for the treatment of gastric varices: a multicenter study (with videos). Gastrointest Endosc 2013;78: 711-21.

5. Weilert F, Shah JN, Marson FP, et al. EUS-guided coil and glue for bleeding rectal varix. Gastrointest Endosc 2012;76:915-6. 
6. Ganguly S, Sarin SK, Bhatia V, et al. The prevalence and spectrum of colonic lesions in patients with cirrhotic and noncirrhotic portal hypertension. Hepatology 1995;21:1226-31.

7. Mukkada RJ, Chooracken M, Antony R, et al. EUS-guided coiling for bleeding duodenal collateral vessel:[abstract]. Gastrointest Endosc 2016;84:1057-8.

8. Wiechowska-Kozłowska A, Białek A, Milkiewicz P. Prevalence of "deep"rectal varices in patients with cirrhosis: an EUS-based study. Liver Int 2009;29:1202-5.

9. Sharma M, Somasundaram A. Massive lower Gl bleed from an endoscopically inevident rectal varices: diagnosis and management by EUS (with videos). Gastrointest Endosc 2010;72:1106-8.

10. Romero-Castro R, Pellicer-Bautista F, Giovannini M, et al. Endoscopic ultrasound (EUS)-guided coil embolization therapy in gastric varices. Endoscopy 2010;42:2009-10.
11. Messallam AA, Kumbhari V, Saxena $P$, et al. Large bleeding rectal varices treated with endoscopic ultrasound-guided coiling and cyanoacrylate injection. Endoscopy 2014;46:E28-9.

Department of Gastroenterology (1); Department of Radiology (2); Department of Gastroenterology, VPS Lakeshore Hospital, Kochi, Kerala, India (3).

Copyright (C) 2017 American Society for Gastrointestinal Endoscopy. Published by Elsevier Inc. This is an open access article under the CC BYNC-ND license (http://creativecommons.org/licenses/by-nc-nd/4.0/).

http://dx.doi.org/10.1016/j.vgie.2017.05.005 